\section{Psychological Medicine}

cambridge.org/psm

\section{Original Article}

*These authors contributed equally to this work.

Cite this article: Becker HC, Norman LJ, Yang $\mathrm{H}$, Monk CS, Phan KL, Taylor SF, Liu Y, Mannella K, Fitzgerald KD (2023). Disorder-specific cingulo-opercular network hyperconnectivity in pediatric OCD relative to pediatric anxiety. Psychological Medicine 53, 1468-1478. https:// doi.org/10.1017/S0033291721003044

Received: 28 December 2020

Revised: 17 May 2021

Accepted: 13 July 2021

First published online: 16 August 2021

\section{Keywords:}

Brain connectivity; cingulo-opercular network; OCD; orbito-striatal-thalamic network; pediatric anxiety

\section{Author for correspondence:}

Hannah C. Becker,

E-mail: hcbecker@umich.edu

\section{Disorder-specific cingulo-opercular network hyperconnectivity in pediatric OCD relative to pediatric anxiety}

\author{
Hannah C. Becker ${ }^{1, \star}$ (D), Luke J. Norman ${ }^{2,3, \star}$, Huan Yang ${ }^{2,4}$, Christopher S. Monk ${ }^{1,2}$, \\ K. Luan Phan ${ }^{5}$, Stephan F. Taylor ${ }^{2}$, Yanni Liu², Kristin Mannella² \\ and Kate D. Fitzgerald ${ }^{1,2}$
}

\begin{abstract}
${ }^{1}$ Department of Psychology, University of Michigan, Ann Arbor, MI, USA; ${ }^{2}$ Department of Psychiatry, University of Michigan, Ann Arbor, MI, USA; ${ }^{3}$ National Human Genome Research Institute, Bethesda, MD, USA; ${ }^{4}$ The Second Xiangya Hospital, Central South University, Changsha, China and ${ }^{5}$ Department of Psychiatry and Behavioral Health, The Ohio State University, Columbus, OH, USA
\end{abstract}

\begin{abstract}
Background. Prior investigation of adult patients with obsessive compulsive disorder (OCD) has found greater functional connectivity within orbitofrontal-striatal-thalamic (OST) circuitry, as well as altered connectivity within and between large-scale brain networks such as the cingulo-opercular network (CON) and default mode network (DMN), relative to controls. However, as adult OCD patients often have high rates of co-morbid anxiety and long durations of illness, little is known about the functional connectivity of these networks in relation to OCD specifically, or in young patients near illness onset.

Methods. In this study, unmedicated female patients with OCD (ages 8-21 years, $n=23$ ) were compared to age-matched female patients with anxiety disorders $(n=26)$, and healthy female youth $(n=44)$. Resting-state functional connectivity was used to determine the strength of functional connectivity within and between OST, CON, and DMN.

Results. Functional connectivity within the CON was significantly greater in the OCD group as compared to the anxiety and healthy control groups. Additionally, the OCD group displayed greater functional connectivity between OST and CON compared to the other two groups, which did not differ significantly from each other.

Conclusions. Our findings indicate that previously noted network connectivity differences in pediatric patients with OCD were likely not attributable to co-morbid anxiety disorders. Moreover, these results suggest that specific patterns of hyperconnectivity within CON and between CON and OST circuitry may characterize OCD relative to non-OCD anxiety disorders in youth. This study improves understanding of network dysfunction underlying pediatric OCD as compared to pediatric anxiety.
\end{abstract}

\section{Introduction}

Obsessive compulsive disorder (OCD) is a debilitating condition that affects $2-3 \%$ of the U.S. population (Ruscio, Stein, Chiu, \& Kessler, 2010) through recurring and unwanted thoughts (obsessions) and the repetitive behaviors aimed at lessening obsession-associated anxiety [compulsions; American Psychiatric Association (APA), 2013]. In addition to OCD-specific symptoms, $50-75 \%$ of adult U.S. OCD patients also suffer from co-morbid anxiety and over $60 \%$ experience a mood disorder (Janowitz et al., 2009; Ruscio et al., 2010). In pediatric OCD, mood disorders are less common (Brakoulias et al., 2017; Ivarsson, Melin, \& Wallin, 2008); however, co-occurring anxiety symptoms are prevalent, with $45-60 \%$ of pediatric OCD patients also meeting criteria for one or more anxiety disorders (Ivarsson et al., 2008; Tanidir et al., 2015). This comorbidity complicates the separation of OCD-specific pathology from non-OCD anxiety pathology, even in affected children who are near illness onset and less likely than adults to have developed additional psychopathology (e.g. depression) or medication exposures that may impact neural circuitry underlying OCD. Gender differences have also been observed in OCD. OCD tends to be more common in boys than girls in childhood, but in adolescence and adulthood, the reverse pattern is observed (Mathes, Morabito, \& Schmidt, 2019). Differences in the symptom dimensions, symptom severity, and co-morbidities experienced between males and females with OCD have also been identified (Mathes et al., 2019). For example, higher rates of some anxiety disorders in female than male youth with OCD have been reported (Masi et al., 2010), consistent with greater prevalence and severity of anxiety disorders in females than males in the general population (Beesdo, Knappe, \& Pine, 2009).

Previous models of the pathophysiology of OCD have focused on dysfunction within the corticostriatal circuits of the brain. These circuits are anatomically segregated loops involved 
in goal-directed behavior, that pass through the cortex, the striatum, the thalamus, and then back to cortex (Alexander, DeLong, \& Strick, 1986; Haber, 2016). Using neuroimaging tools such as functional magnetic resonance imaging (fMRI) and positron-emission tomography, researchers have found that corticostriatal system activity in patients with OCD increases during symptom provocation and resolves after effective treatment (Menzies et al., 2008; Nakao, Okada, \& Kanba, 2014; Saxena \& Rauch, 2000). Within this corticostriatal system, in contrast to healthy individuals, OCD is most consistently associated with dysregulation in orbitofrontal cortex (OFC), dorsal striatal, and thalamic regions of an orbitofrontal-striatal-thalamic (OST) circuit in both children and adults (Fitzgerald et al., 2011; Kodaira et al., 2012; Norman et al., 2019; Rosenberg \& Keshavan, 1998). In addition to OST hyperactivity during symptom provocation (Banca et al., 2015; Breiter et al., 1996; Brennan et al., 2015), compared to healthy controls (HCs), adults with OCD exhibit OST hyperactivity during habit-responding, but hypoactivity during inhibitory control and reward tasks (Kang et al., 2013; Norman et al., 2018, 2019). Prior resting-state fMRI research has revealed hyperconnectivity of regions in the OST circuit, suggestive of excess signaling in adults and children with OCD compared to HCs (Apergis-Schoute et al., 2018; Fitzgerald et al., 2011; Harrison et al., 2009; Hou et al., 2014; Jang et al., 2010; Sakai et al., 2011).

Extending beyond the study of corticostriatal circuitry, neuroimaging research of OCD has examined potential differences in the behavior of large-scale intrinsic functional brain networks (Peterson, Thome, Frewen, \& Lanius, 2014; Posner et al., 2017; Stern, Fitzgerald, Welsh, Abelson, \& Taylor, 2012; Tian et al., 2016), such as the cingulo-opercular network (CON) and the default mode network (DMN). Intrinsic networks such as the CON and DMN can be identified with resting-state fMRI as distributed regions that display highly correlated patterns of a lowfrequency blood-oxygen-level-dependent signal. These correlations are thought to index functional connectivity between regions that are anatomically connected, as demonstrated by tract-tracing studies in non-human primates (Carmichael \& Price, 1996; Goldman-Rakic, 1988; Haber, 2003; Mesulam, 1990). The CON encompasses posterior medial frontal cortex (pMFC) and fronto-operculum (Norman et al., 2019; Power et al., 2011; Sestieri, Corbetta, Spadone, Romani, \& Shulman, 2014) and is engaged when directing attention externally to salient events in the environment (Dosenbach et al., 2006; Neta, Schlaggar, \& Petersen, 2014). A meta-analysis that included studies of both children and adults found CON hyperactivity during error-processing in addition to CON hypoactivity during inhibitory control in patients with OCD as compared to HCs. These findings implicate the $\mathrm{CON}$ in cognitive processes that may prevent patients from stopping unwanted thoughts or behaviors that occur (Norman et al., 2019). Previous studies have shown an altered relationship within and between the CON and other brain networks at rest in OCD patients in contrast to HCs (Fan et al., 2017; Tomiyama et al., 2019), particularly the DMN (Beucke et al., 2014), and including in pediatric patients (Fitzgerald et al., 2010).

The DMN is comprised of nodes in posterior cingulate cortex (PCC), precuneus, ventral medial prefrontal cortex (vmPFC), angular gyrus (AG), and medial temporal cortex (Andrews-Hanna, Reidler, Huang, \& Buckner, 2010; Fransson \& Marrelec, 2008; Greicius, Krasnow, Reiss, \& Menon, 2003). The DMN deactivates during external cognitively demanding tasks (Gusnard \& Raichle, 2001; Shulman et al., 1997), and is inversely correlated with the CON (Fox et al., 2005). Relative to healthy individuals, in pediatric and adult patients with OCD, regions of the DMN have been shown to deactivate to a lesser degree during externally oriented tasks (Brennan et al., 2015; Stern et al., 2011, 2012), to have reduced connectivity with each other (Fitzgerald et al., 2010; Peng et al., 2014), and in some instances, display greater connectivity with other large-scale networks, including the CON (Beucke et al., 2014; Harrison et al., 2013; Hou et al., 2013; Posner et al., 2017; Yun et al., 2020). Since the DMN is engaged during introspective, self-referential processing, prior research has noted the potential role of the DMN in generating repetitive patterns of thinking associated with OCD (Stern et al., 2012).

Although earlier research provides strong support for the involvement of OST, CON, and DMN circuits in OCD, several methodological limitations hinder conclusions about the specificity of findings. For example, OCD patients in these studies are often taking selective serotonin reuptake inhibitors (e.g. Apergis-Schoute et al., 2018; Beucke et al., 2014; Fitzgerald et al., 2010, 2011), which have been found to change OST connectivity in youth with OCD (Bernstein et al., 2019). Furthermore, most studies of unmedicated OCD compared to HC groups include adult patients, who have likely experienced OCD symptoms for many years at the time of the study (Chen et al., 2018; Hou et al., 2013; Posner et al., 2014; Sakai et al., 2011). Consequently, the relationship between these large-scale brain networks at the early-stages of OCD onset, without the effects of compensatory neural response or pharmacological treatment, is not well understood. Furthermore, as prior research has historically sampled OCD patients with high rates of co-morbid anxiety disorders (Beucke et al., 2014; Chen et al., 2018; Cocchi et al., 2012; Fitzgerald et al., 2013; Harrison et al., 2013; Hou et al., 2012; Jang et al., 2010; Jung et al., 2017; Sylvester et al., 2012), it remains unclear to what extent the differences in within- and between-network connectivity in 'OCD groups' are specific to OCD. However, studies that examined resting-state network connectivity in adults with OCD and non-OCD anxiety independently have found dysfunctional connectivity in both the DMN and the CON as compared to HCs (Beucke et al., 2014; Peterson et al., 2014; Rabany et al., 2017; Xu et al., 2019). However, few studies have directly examined resting-state connectivity of the OST, CON, or DMN in anxiety disorders without OCD (Peterson et al., 2014; Sylvester et al., 2012), leaving the alterations of large-scale intrinsic networks that may differentiate between these disorders relatively unexplored.

The current study builds upon prior neuroimaging research showing evidence for dysfunction in OST, CON, and DMN in pediatric OCD. Our predictions were informed by a large body of research that supports alterations of OST circuitry in OCD, in contrast to relatively minimal evidence implicating this circuitry in non-OCD anxiety disorders (Peterson et al., 2014; Sylvester et al., 2012). Specifically, we hypothesized that there would be hyperconnectivity within the OST circuit in the OCD group compared to the other two groups and that any differences in connectivity strength between the OST network and the CON or DMN would be unique to OCD patients. In contrast, we hypothesized that differences in within-network DMN or CON connectivity, as well as between-network CON to DMN connectivity, would be shared by both the OCD and anxiety control (AC) groups, consistent with previously published theoretical models and empirical research (de Vries et al., 2019; Fitzgerald et al., 2010; Shanmugan et al., 2016; Sylvester et al., 2012). Based on this research, we expected to see hyperconnectivity within the CON and between the CON and DMN in both the OCD and AC groups as compared to the HC group. 


\section{Methods}

\section{Participants}

Ninety-seven unmedicated females aged 8-21 years with a primary diagnosis of OCD $(n=25)$, one or more non-OCD anxiety disorders $(n=27)$, or no diagnosis $(n=45)$ underwent restingstate fMRI at the University of Michigan Medical School (UMMS). Early-onset OCD more commonly affects young boys whereas later-onset $\mathrm{OCD}$ and non-OCD anxiety disorders are more common in girls (Mathis et al., 2011; Merikangas et al., 2010); thus, the inclusion of only girls eliminated potential confounding between groups by gender representation and age. Primary diagnosis determined group membership and was defined by the primary source of impairment at study entry, based on structured clinical interview using the Kiddie Schedule for Affective Disorders and Schizophrenia, or the Structured Clinical Interview for DSM-V if the subject was 18 years or older. Secondary (i.e. lower severity) anxiety disorders were included in the OCD group. By contrast, no OCD diagnoses were present among patients in the AC group. For generalizability, patients with co-morbid tic, anxiety, dysthymia, or depression not otherwise specified were included as long as OCD (in the OCD group), or a non-OCD anxiety disorder was the primary source of impairment. Major depressive disorder was absent from the OCD group but occurred as a secondary diagnosis (i.e. less impairing) in two patients in the AC group. Attention-deficit/ hyperactivity, autism spectrum, psychotic, and bipolar disorders were excluded. HC group members had no current or past history of psychiatric disorder. All participants reported no history of head trauma, serious medical/neurological illness, or MRI contraindications. Prior to participation in the study, and after thorough description of the study to potential participants and their parents, written informed consent/assent was obtained. Two participants were excluded due to technical problems resulting from poor co-registration, one patient was excluded due to an incidental brain finding, and one patient was excluded due to excessive motion. As a result of these exclusions (two OCD, one AC, and one $\mathrm{HC}$ ), a total of 93 participants were included in the subsequent analyses. The research protocols described in this paper were approved by the Institutional Review Board within the UMMS (IRB numbers: HUM3920 and HUM00039079). Additional participant details are provided in Table 1.

\section{Assessment of symptom severity and subtypes}

OCD and anxiety symptoms were assessed in all subjects using the Obsessive Compulsive Inventory-Revised (OCI-R) and Multidimensional Anxiety Scale for Children (MASC). Symptom types were assessed with the OCI-R subscales. One-way analyses of variance were run to evaluate group differences in OCI-R and MASC scores. Symptom severity within the OCD patient group was also assessed using the appropriate child or adult version of the Yale-Brown Obsessive Compulsive Scale (C/Y-BOCS; Goodman et al., 1989).

\section{Imaging procedures/acquisition}

Neuroimaging data were acquired on a 3.0T GE Signa scanner (General Electric, Milwaukee, Wisconsin) located at the University of Michigan Medical School. See online Supplement for details.

\section{Image preprocessing}

Standard preprocessing of the imaging data was conducted using Data Processing \& Analysis of Brain Imaging (DPABI; Yan, Wang, Zuo, and Zang, 2016) and Statistical Parametric Mapping (SPM12; https://www.fil.ion.ucl.ac.uk/spm/software/ spm12/; Friston, 2003). See online Supplement for details.

\section{Functional connectivity analyses}

We focused on OST, CON, and DMNs implicated in our previous study on OCD (Fitzgerald et al., 2011; Norman et al., 2019, 2021; Stern et al., 2012); whereas other networks may be involved in OCD pathology (de Vries et al., 2019; Stern et al., 2012), a concentration on these three networks allowed us to limit multiple comparisons. The OST striatal and thalamic regions of interest (ROIs) were derived from Di Martino et al. (2008) and Fitzgerald et al. (2011). All other ROIs, including the OFC ROI for the OST network, were selected from the Harvard-Oxford atlas distributed with FSL (http://www.fmrib.ox.ac.uk/fsl/), by placing a $5-\mathrm{mm}$ spherical radius around the (approximate) center of each region as given by FSLview (https://fsl.fmrib.ox.ac.uk/fsl/ fslwiki/FslView; Smith et al., 2004). ROIs for the DMN and CON were selected from previous categorizations of regions displaying patterns of correlated activity within each of these networks. The CON was composed of pMFC sub-regions in the dorsal anterior cingulate cortex (dACC), pre-supplementary motor area, and supplementary motor areas, as well as the frontal operculum, and anterior insula (Norman et al., 2019; Seeley et al., 2007). For the DMN, regions in precuneus, PCC, medial frontal pole, medial frontal gyrus, medial temporal lobe (MTL), and AG were selected (Yeo et al., 2011). Coordinates and corresponding Harvard-Oxford labels are provided in Table 2.

Time courses from all voxels within a $5-\mathrm{mm}$ spherical radius around each of the ROI coordinates were averaged and then correlated with each other, thereby creating an ROI-to-ROI connectivity matrix for each subject containing all ROIs from the three networks (ROI coordinates are provided in Table 2). Fisher's $r$-to- $z$ transformation was then applied to each cell of the resultant matrices. Within network connectivity was determined for $a$ priori defined OST, CON, and DMNs by averaging the Fisher-z-transformed correlation coefficients for all intra-network correlations of each ROI, within each network, for each subject. Between network connectivity was calculated for each pairwise combination of networks (OST to CON, OST to DMN, and CON to DMN) by averaging all of the Fisher- $z$-transformed correlation coefficients of inter-network connections between each ROI of each of the two networks included in the network pair, for each subject. Separate one-way analysis of covariance (ANCOVA) models, including covariates of age and mean framewise displacement (FD), were used to compare the OCD, AC, and $\mathrm{HC}$ groups on measures of within network connectivity in each network, and network connectivity between each of the three networks. These tests were corrected for multiple comparisons using the Benjamini and Hochberg method (false-discovery rate; FDR; Benjamini and Hochberg, 1995). In order to interpret the group differences from the between-group ANCOVA, functional connectivity estimates were plotted in raincloud plots (Allen, Poggiali, Whitaker, Marshall, \& Kievit, 2019), subjected to pairwise ( $\mathrm{OCD} v$. AC, OCD v. HC, AC v. HC group) post-hoc $t$ tests, and corrected for multiple comparisons for three groups using the least significance difference method (Fisher, 1935) 


\begin{tabular}{|c|c|c|c|c|}
\hline & & Group & & \\
\hline & $O C D$ & $A C$ & $\mathrm{HC}$ & Statistic \\
\hline N & 23 & 26 & 44 & \\
\hline Age & $14.00(3.84)$ & $13.38(3.20)$ & $14.55(3.88)$ & $\begin{array}{l}F=0.82 \\
p=0.445\end{array}$ \\
\hline Race & $\begin{array}{l}\text { American Indian or Alaska Native: } 1 \\
\text { Asian: } 1 \\
\text { Black or African American: } 1 \\
\text { Caucasian: } 18 \\
\text { Multi-race: } 1 \\
\text { Other: } 1\end{array}$ & $\begin{array}{l}\text { American Indian or Alaska Native: N/A } \\
\text { Asian: } 1 \\
\text { Black or African American: } 5 \\
\text { Caucasian: } 17 \\
\text { Multi-race: } 1 \\
\text { Other: } 2\end{array}$ & $\begin{array}{l}\text { American Indian or Alaska Native: N/A } \\
\text { Asian: } 3 \\
\text { Black or African American: } 4 \\
\text { Caucasian: } 29 \\
\text { Multi-race: } 6 \\
\text { Other: } 2\end{array}$ & $\mathrm{~N} / \mathrm{A}$ \\
\hline MASC total ${ }^{a}$ & $\begin{array}{l}57.11(18.61) \\
n=18\end{array}$ & $\begin{array}{l}57.12(21.08) \\
n=26\end{array}$ & $\begin{array}{l}30.53(14.76) \\
n=38\end{array}$ & $F=22.72, p<0.001$ \\
\hline Y-BOCS total & $23.03(6.41)$ & $\mathrm{N} / \mathrm{A}$ & $\mathrm{N} / \mathrm{A}$ & $\mathrm{N} / \mathrm{A}$ \\
\hline OCI-R total ${ }^{\mathrm{a}}$ & $\begin{array}{l}26.39(14.10) \\
n=18\end{array}$ & $\begin{array}{l}12.04(14.26) \\
n=23\end{array}$ & $\begin{array}{l}6.29(9.77) \\
n=41\end{array}$ & $\begin{array}{l}F=17.11 \\
p<0.001\end{array}$ \\
\hline OCI-R checking ${ }^{a}$ & $\begin{array}{l}3.06(3.04) \\
n=18\end{array}$ & $\begin{array}{l}1.73(2.66) \\
n=22\end{array}$ & $\begin{array}{l}0.86(1.93) \\
n=37\end{array}$ & $\begin{array}{l}F=4.92 \\
p=0.010\end{array}$ \\
\hline OCl-R washing ${ }^{a}$ & $\begin{array}{l}4.64(4.36) \\
n=18\end{array}$ & $\begin{array}{l}1.22(2.05) \\
n=22\end{array}$ & $\begin{array}{l}0.75(1.86) \\
n=37\end{array}$ & $\begin{array}{l}F=13.16 \\
p<0.001\end{array}$ \\
\hline OCl-R ordering ${ }^{a}$ & $\begin{array}{l}5.92(3.33) \\
n=18\end{array}$ & $\begin{array}{l}3.00(4.19) \\
n=22\end{array}$ & $\begin{array}{l}1.68(2.31) \\
n=37\end{array}$ & $\begin{array}{l}F=10.77 \\
p<0.001\end{array}$ \\
\hline OCI-R obsessing ${ }^{a}$ & $\begin{array}{l}5.42(4.68) \\
n=18\end{array}$ & $\begin{array}{l}2.73(3.81) \\
n=22\end{array}$ & $\begin{array}{l}0.57(1.46) \\
n=37\end{array}$ & $\begin{array}{l}F=14.21 \\
p<0.001\end{array}$ \\
\hline OCl-R hoarding ${ }^{\mathrm{a}}$ & $\begin{array}{l}3.89(3.32) \\
n=18\end{array}$ & $\begin{array}{l}2.32(2.66) \\
n=22\end{array}$ & $\begin{array}{l}2.32(2.45) \\
n=37\end{array}$ & $\begin{array}{l}F=2.27 \\
p=0.111\end{array}$ \\
\hline OCI-R neutralizing ${ }^{a}$ & $\begin{array}{l}3.47(3.76) \\
n=18\end{array}$ & $\begin{array}{l}1.22(3.05) \\
n=22\end{array}$ & $\begin{array}{l}0.41(1.32) \\
n=37\end{array}$ & $\begin{array}{l}F=8.48 \\
p<0.001\end{array}$ \\
\hline FD & $0.17(0.11)$ & $0.21(0.25)$ & $0.40(0.90)$ & $\begin{array}{l}F=1.31 \\
p=0.275\end{array}$ \\
\hline $\begin{array}{l}\text { Comorbid tic, anxiety, } \\
\text { and depressive }{ }^{b} \text { disorders }\end{array}$ & $\begin{array}{l}\text { Tics: } 1 \\
\text { Anxiety: } 8 \\
\text { Depressive: } 4\end{array}$ & $\begin{array}{l}\text { Tics: } 2 \\
\text { Anxiety: } 11 \\
\text { Depressive: } 8\end{array}$ & $\begin{array}{l}\text { Tics: } 0 \\
\text { Anxiety: } 0 \\
\text { Depressive: } 0\end{array}$ & $\mathrm{~N} / \mathrm{A}$ \\
\hline
\end{tabular}

Y-BOCS, Yale-Brown Obsessive Compulsive Scale; FD, framewise displacement.

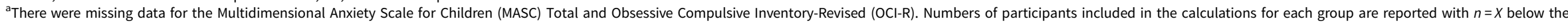
group means in the associated columns when there is missing data.

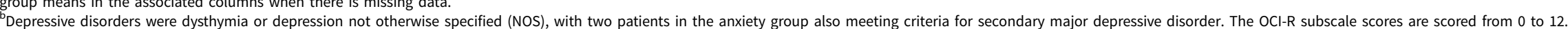


Table 2. Region labels and coordinates for CON, DMN, and OST ROIs

\begin{tabular}{|c|c|c|c|}
\hline Region & Harvard-Oxford label & MNI: $x, y, z$ & Network \\
\hline Insula & Insular cortex & $+/-40,14,-8$ & CON \\
\hline Frontal operculum & Frontal operculum cortex & $+/-42,22,2$ & CON \\
\hline Dorsal anterior cingulate cortex & Cingulate gyrus, anterior division & $0,-4,42$ & CON \\
\hline Supplementary motor cortex & Juxtapositional lobule cortex (formerly supplementary motor cortex) & $0,0,54$ & CON \\
\hline Pre-supplementary cortex & Paracingulate gyrus & $0,34,32$ & CON \\
\hline Precuneus & Precuneus cortex & $0,-64,38$ & DMN \\
\hline Posterior cingulate cortex & Cingulate gyrus, posterior division & $0,-42,36$ & DMN \\
\hline Medial temporal lobe & Middle temporal gyrus, posterior division & $+/-58,-8,-20$ & DMN \\
\hline Angular gyrus & Angular gyrus & $+/-48,-52,38$ & DMN \\
\hline Anterior medial prefrontal cortex & Frontal pole & $0,62,-2$ & DMN \\
\hline Ventromedial prefrontal cortex & Frontal medial cortex & $0,42,-18$ & DMN \\
\hline Caudate & - & $+/-13,15,9$ & OST \\
\hline Putamen & - & $+/-28,1,3$ & OST \\
\hline Thalamus & - & $+/-8,-14,8$ & OST \\
\hline Orbitofrontal cortex & Frontal orbital cortex & $+/-26,36,-13$ & OST \\
\hline
\end{tabular}

MNI, Montreal Neurological Institute. CON, Cingulo-opercular network; DMN, Default mode network; OST, Orbitofrontal-striatal-thalamic circuit.

(Fig. 1). The ROIs for the three networks are depicted on a glass brain in Figure 2.

\section{Results}

\section{Clinical characteristics}

The average C/Y-BOCS score was 23.03 (6.41), indicating that OCD patients were experiencing symptoms of moderate severity. In the anxiety group, primary diagnoses were generalized anxiety disorder $(n=12)$, social anxiety disorder $(n=8)$, specific phobia $(n=3)$, panic disorder $(n=1)$, and separation anxiety disorder $(n=2) ; 10$ patients had additional anxiety diagnoses (see Table 1). As expected, OCI-R scores were greater for the OCD group than that for the AC or HC groups. Scores on the MASC were greater in both the $\mathrm{OCD}$ and $\mathrm{AC}$ groups as compared to the HC group, and were similar between patient groups, reflecting the high rates of anxiety disorders typically observed in pediatric OCD (Geller et al., 2001; see Table 1). There were no group differences in mean age $\left(F_{(2,90)}=0.82, p=0.45\right)$ or $\mathrm{FD}\left(F_{(2,90)}=1.31, p=\right.$ $0.28)$ and no significant correlation between FD and age $(r(91)=$ $-0.01, p=0.90$ ). See Table 1 for full descriptive and test statistics.

\section{Functional connectivity results}

Functional connectivity within and between the OST, CON, and DMNs was assessed for group differences, controlling for age and mean FD. Main findings were group differences in connectivity within the $\operatorname{CON}\left(F_{(2,88)}=4.91, p=0.010\right.$, FDR-adjusted $p=0.045$, $\left.\eta_{\mathrm{p}}^{2}=0.10\right)$ and between the CON and OST networks $\left(F_{(2,88)}=\right.$ $4.38, p=0.015$, FDR-adjusted $\left.p=0.045, \eta_{\mathrm{p}}^{2}=0.09\right)$. Post-hoc tests revealed that within-network connectivity of the $\mathrm{CON}$ was greater in the OCD group $(M=0.54$, S.E. $=0.027)$ than that in the AC $(M$ $=0.43$, S.E. $=0.025, p=0.003)$ or HC groups $(M=0.46$, S.E. $=$ $0.020, p=0.027)$. The AC group and HC group did not differ on the measure of within-CON connectivity $(p=0.238)$.
Additionally, CON-OST between-network connectivity was greater in the OCD group $(M=0.40$, S.E. $=0.027)$ than either the AC $(M=0.30$, S.E. $=0.025, p=0.004)$ or HC $(M=0.33$, S.E. $=0.020$, $p=0.043)$ groups, which were not different from each other $(p=0.228)$. There were no further significant group differences in within- or between-network connectivity (all FDR-adjusted $p>0.214)$. Means and standard deviations for connectivity in and between the networks are reported in Table 3 .

\section{Secondary analyses}

The C/Y-BOCS, collected only for the OCD group, was not significantly correlated with any of the six within- or between-connectivity metrics among OCD patients. In addition, the MASC was collected for most participants $(n=82)$, and was not significantly correlated with any functional connectivity metric in the three groups. The findings within- $\mathrm{CON}$ and between $\mathrm{CON}-\mathrm{OST}$ remained significant after including an extra covariate for co-morbid depressive disorder. Additionally, the results held when participants ages $>18$ were excluded (see online Supplement).

\section{Discussion}

The current study evaluated functional connectivity within and between the OST, CON, and DMN in patients with OCD as compared to AC and HC groups in female youth. Group differences were observed in two main domains. Specifically, a pattern of hyperconnectivity within the CON, and between the CON and OST networks, was found in the OCD group as compared to the other two groups at rest. Although we hypothesized that groups would differ in connectivity strength related to these networks, the pattern of differences between groups did not entirely match our expectations. For instance, among the three networks studied, we expected that only OST connectivity would distinguish the OCD from the anxiety disorder group; however, we 
(a)

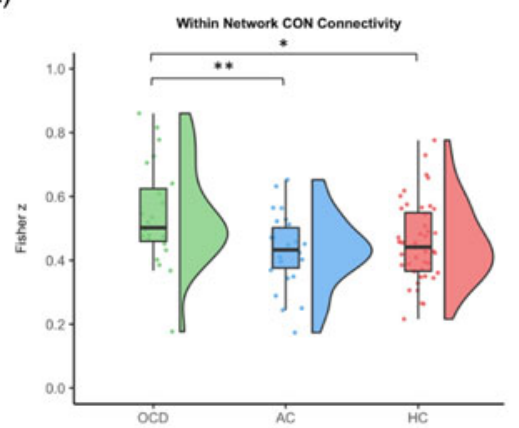

(d)

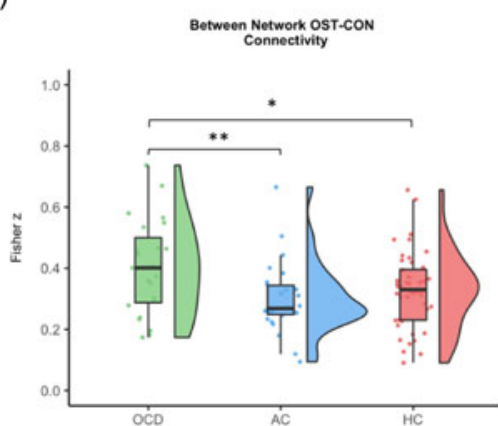

(b)

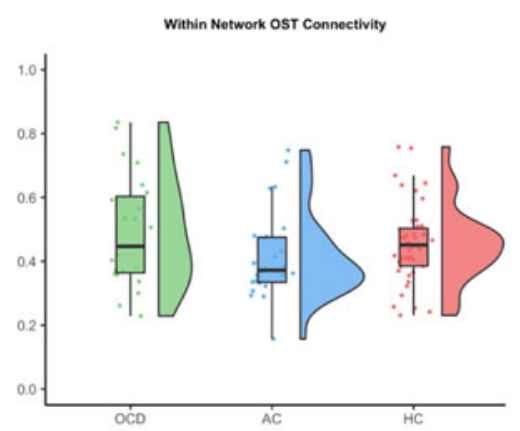

(e)

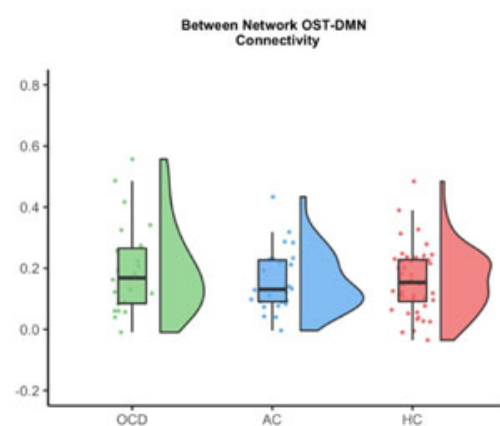

(c)

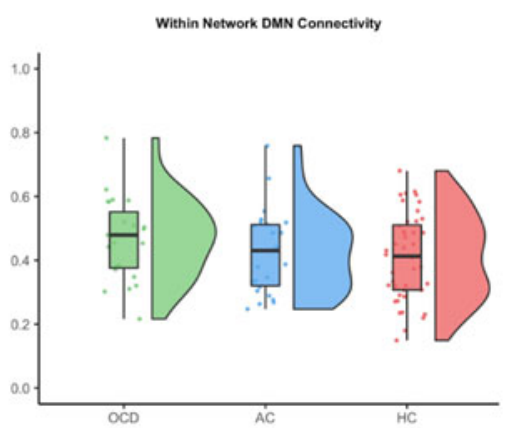

(f)

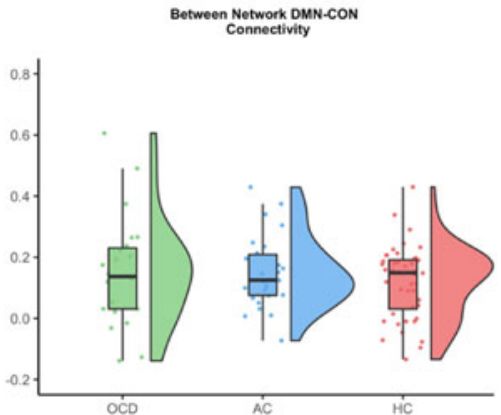

Figure 1. Raincloud plots displaying group differences in network connectivity within and between the CON, OST, and DMN. The OCD group is shown in green, the anxiety control group in blue, and the healthy control group in red. Each subfigure describes connectivity (a) within-CON, (b) within-OST, (c) within-DMN, (d) between OST-CON, (e) between OST-DMN, and ( $f$ ) between DMN-CON. Note. Significance of post-hoc pairwise comparisons between groups is indicated with asterisks. ${ }^{\star}$ Refers to a significant difference between groups at $p<0.05$. ${ }^{\star \star}$ Refers to a significant difference between groups at $p<0.01$.
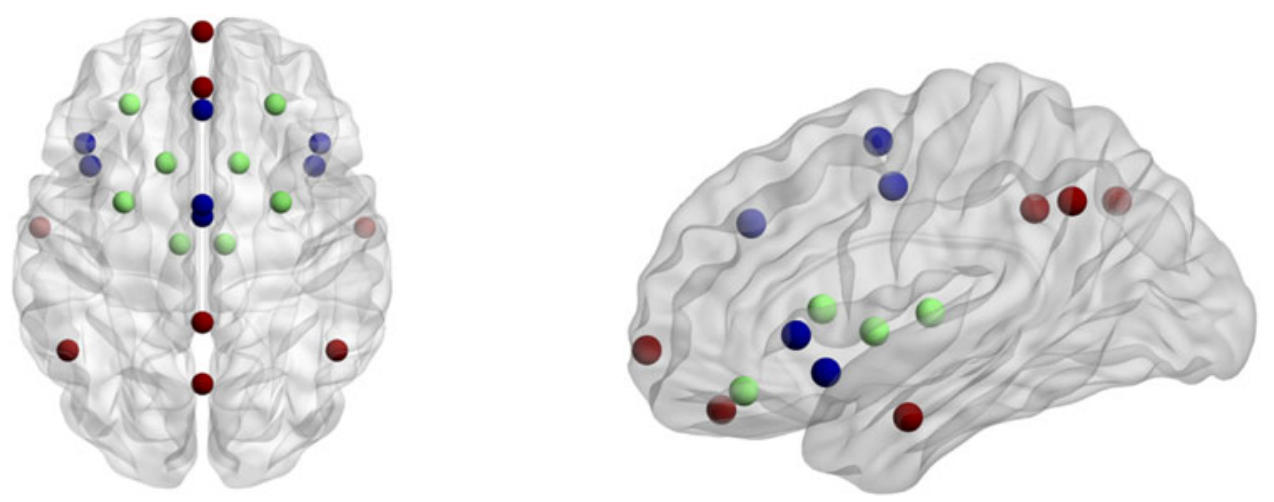

Figure 2. Bilateral ROIs of the OST (green), CON (blue), and DMN (red) presented on a glass brain. Region labels and coordinates are given in Table 2.

found that connectivity differed within $\mathrm{CON}$ and between the CON and OST circuit for OCD youth relative to the AC youth. Within-CON hyperconnectivity was hypothesized for both OCD and AC groups, but was displayed only in the OCD group. Notably, the findings presented here indicate that there are connectivity profiles that are unique to female pediatric patients with OCD and not shared by age-matched patients with anxiety disorders.

\section{Within CON hyperconnectivity}

The OCD group displayed significantly greater connectivity within the CON than the AC or HC groups. Evidence of taskbased hyperactivity of the $\mathrm{CON}$ during error processing
(Norman et al., 2019) is consistent with work implicating the CON broadly in functions of performance and error monitoring (Dosenbach, Fair, Cohen, Schlaggar, \& Petersen, 2008; Neta et al., 2014; Sylvester et al., 2012), tonic alertness (Marek \& Dosenbach, 2019), and electrophysiological studies demonstrating greater CON response to errors in patients with OCD (Gehring, Himle, \& Nisenson, 2000; Hajcak, Franklin, Foa, \& Simons, 2008; Hauser et al., 2017; Maltby, Tolin, Worhunsky, O’Keefe, \& Kiehl, 2005). Although hyperconnectivity between these regions does not necessarily dictate task-related hyperactivity of these regions, a previous study found that when greater tonic alertness was required during a task, the regions of the CON became increasingly connected and active (Sadaghiani \& D'Esposito, 2015). Therefore, it is possible that hyperconnectivity of the 
Table 3. Mean and standard deviations (S.D.) of within-network and between-network connectivity for the three groups

\begin{tabular}{|c|c|c|c|c|c|c|c|}
\hline \multirow[b]{2}{*}{ Network connectivity } & \multicolumn{2}{|c|}{ OCD group } & \multicolumn{2}{|c|}{$A C$ group } & \multicolumn{2}{|c|}{ HC group } & \multirow{2}{*}{$\begin{array}{c}\text { ANCOVA result } \\
\text { pFDR }\end{array}$} \\
\hline & Mean & S.D. & Mean & S.D. & Mean & S.D. & \\
\hline Within-CON* & 0.54 & 0.16 & 0.43 & 0.11 & 0.46 & 0.12 & 0.045 \\
\hline Within-DMN & 0.47 & 0.13 & 0.42 & 0.13 & 0.41 & 0.14 & 0.426 \\
\hline Within-OST & 0.49 & 0.17 & 0.42 & 0.14 & 0.45 & 0.12 & 0.214 \\
\hline CON-OST* & 0.40 & 0.16 & 0.30 & 0.12 & 0.33 & 0.13 & 0.045 \\
\hline DMN-CON & 0.15 & 0.18 & 0.15 & 0.12 & 0.12 & 0.12 & 0.627 \\
\hline OST-DMN & 0.20 & 0.15 & 0.16 & 0.10 & 0.16 & 0.11 & 0.478 \\
\hline
\end{tabular}

OCD, obsessive compulsive disorder; AC, anxiety control; HC, healthy control; CON, cingulo-opercular network; DMN, default mode network; OST, orbitofrontal-striatal-thalamic; pFDR, false-discovery rate corrected $p$-value. * Refers to cases where there was a significant group difference in connectivity.

CON at rest in patients with OCD still reflects a hyperactive error monitoring mechanism even when no error is actively being made. This excessive error monitoring may translate to a pathological response in patients with OCD, for instance, as attempts are made to reduce error signals through repetitive behaviors or rituals (Hajcak et al., 2008; Pitman, 1987).

Greater error-related CON activity in OCD may reflect a pathologic (Hajcak et al., 2008) or a compensatory response (Fitzgerald et al., 2018; Moser, 2017) but, in either case, heightened levels of error-signaling within the CON could impact connectivity. Indeed, repeated cognitive activity has been found to increase connectivity of intrinsic networks (Lewis \& Kim, 2009) such that, over time, high levels of error signaling in OCD could increase connections between CON nodes. To understand the possible influence of $\mathrm{CON}$ error-monitoring activity on CON connectivity in OCD, longitudinal research will need to examine the dynamic relationships between task-related and resting-state function of the CON over time. In theory, such research could especially benefit from the study of young patients, near illness onset, to capture any changes in connectivity resulting from a compensatory response to the symptoms themselves.

As with OCD, we predicted CON hyperconnectivity in the AC group based on literature suggesting hyperactive function across both disorders (Gillan, Fineberg, \& Robbins, 2017). However, in contrast to OCD, we did not observe the hypothesized effect in AC. In order to distinguish the AC group from the $\mathrm{HC}$ group based on connectivity measures, different networks may need to be assessed. For instance, the frontoparietal network, ventral attention network, and connections between the amygdala and these two networks may be more relevant toward assessing AC-specific pathology (Sylvester et al., 2012). Indeed, meta-analysis suggests reduced anterior cingulate connectivity with amygdala in anxiety, rather than within the CON nodes studied here (Kolesar, Bilevicius, Wilson, \& Kornelsen, 2019).

\section{OST-CON hyperconnectivity}

An additional finding was that the OCD group, compared with the $\mathrm{AC}$ and $\mathrm{HC}$ groups, displayed hyperconnectivity between the OST circuit and the CON. Studies of the OST in OCD, relative to HCs, have found certain regions within this circuit to be anatomically enlarged (Hou et al., 2013), hyperactive and hyperconnected at rest (Harrison et al., 2009; Sakai et al., 2011), during symptom provocation (Breiter et al., 1996), and during habit-responding (Banca et al., 2015), but hypoactive during cognitive control and reward tasks in patients with OCD (Kang et al., 2013; Norman et al., 2019). Alterations in OST-mediated habit and motivation functions have been proposed to underlie an imbalance between competing OCD and goal-related behaviors in the disorder (Gillan et al., 2015). For instance, hyperconnectivity between the OST and CON may represent a greater influence of the habit system (localized to the OST circuit) over the brain circuitry responsible for salience detection and action selection (located in CON), which may manifest as compulsive actions (Chase et al., 2020; Gillan \& Robbins, 2014; Graybiel \& Rauch, 2000; Tomiyama et al., 2019) and cognitive inflexibility (Banca et al., 2015; Gu et al., 2008; Jung et al., 2017).

\section{OCD specificity}

The observed differences in hyperconnectivity within the CON and between the CON and OST networks were unique to the OCD group; the AC group did not display heightened connectivity in and between these networks. These results suggest the potential of an OCD-specific mechanism that is observable in unmedicated, pediatric OCD patients. However, despite finding these differences in the current study, it is evident that OCD and non-OCD anxiety disorders share similar patterns of symptoms. Given these overlapping phenomena, it is also likely that symptoms of OCD and non-OCD anxiety disorders derive common underlying mechanisms (Fitzgerald, Schroder, \& Marsh, 2020). Importantly, we have interpreted these current findings as one mechanism by which OCD may be distinct from non-OCD anxiety, with the understanding that there are likely many shared mechanisms as well, even specific to the functioning of the CON and other large-scale brain networks (Menon, 2011).

The distinct clinical presentation of OCD has led to its removal from the anxiety disorders chapter of The Diagnostic and Statistical Manual of Mental Disorders (5th ed.; DSM-5) into a separate section (APA, 2013; Morillo, Belloch, \& García-Soriano, 2007), consistent with the notion of distinct underlying mechanisms. The current finding of greater within-CON and between CON-OST connectivity in youth with OCD, but not anxiety disorders, may reflect an excess of OST-driven habits and compulsive symptoms that are unique to OCD. However, anxiety symptoms experienced by OCD patients may also impact neural circuitry, and additional study is needed to disentangle mechanistic differences between OCD and 
non-OCD anxiety disorders. Specifically, patients with OCD and anxiety disorders should be studied throughout different phases of development and over time with progression of each symptom class to identify mechanisms that may distinguish these disorders.

\section{Limitations}

Several limitations should be considered when interpreting the findings presented here. First, the sample used in the current study was composed of unmedicated, child, and adolescent female participants. The characteristics of this group allowed us to control for the potential confounding effects of gender (Zhang, Dougherty, Baum, White, \& Michael, 2018) and extended illness as seen in adult patients (Andreescu, Sheu, Tudorascu, Walker, \& Aizenstein, 2014) on intrinsic connectivity networks. However, it is important to consider that findings from the current study may not be generalizable to the broader OCD population. This is especially relevant because, although subtle gender differences in resting-state connectivity have been reported in typically developing youth, no studies to our knowledge have examined gender differences in fMRI studies of OCD. This would be a valuable question to assess in future research.

Additionally, the way in which brain networks are defined can impact connectivity findings (Fox \& Greicius, 2010). Although the networks studied closely resemble their adult state during childhood and adolescence (Gilmore, Knickmeyer, \& Gao, 2018), developmental changes in the relative strength of connections have been demonstrated (Fair et al., 2013; Grayson \& Fair, 2017; Marek, Hwang, Foran, Hallquist, \& Luna, 2015) and standard approaches for mapping connectivity in youth samples (e.g. child-specific brain atlases) are needed in the field and could inform future research.

Third, there was heterogeneity within the AC group. Although each participant in the OCD group had a primary diagnosis of $\mathrm{OCD}$, the individuals in the AC group had primary diagnoses of different anxiety disorders. Finally, although the use of functional connectivity has greatly enhanced our understanding of large-scale brain differences across several psychiatric disorders (Brennan et al., 2019; Harrison et al., 2009; Woodward \& Cascio, 2015), there is still much about this method that we do not understand. Specifically, without knowing the mechanism by which hyper- or hypo-connectivity within or between networks relates to behavior, interpretations of connectivity strength will continue to have limited clinical impact. Studies such as ours help to gain a better understanding of the OCD-specific abnormalities in functional connectivity, but future research will need to evaluate the mechanism by which a difference in connectivity relates to differences in behavior.

\section{Conclusion}

Evaluation of functional connectivity within and between large-scale brain networks has offered an exciting mechanism for exploring neural dysfunction in OCD and anxiety disorders. Extending beyond the study of the anatomical OST circuit in OCD, this study provides new knowledge about potential brain network connectivity differences in the CON and interactions between the CON and the OST network in patients with OCD. Crucially, greater connectivity in and between the CON and OST circuits was found exclusively in young, unmedicated, female patients with OCD when directly compared to young, unmedicated patients with non-OCD anxiety. These findings are an important step toward identifying disorder- or symptom-specific markers for OCD.

Supplementary material. The supplementary material for this article can be found at https://doi.org/10.1017/S0033291721003044

Financial support. This work was funded by the National Institute of Mental Health (KDF and SFT, grant number R01 MH102242; KDF, CSM, and KLP, grant number R01 MH107419; CSM and KLP, grant number R01 MH 086517).

Conflict of interest. All authors (H.C.B., L.J.N., H.Y., C.S.M., K.L.P., S.F.T., Y.L., K.M., and K.D.F.) have no financial conflicts of interest to disclose.

Ethical standards. The authors assert that all procedures contributing to this work comply with the ethical standards of the relevant national and institutional committees on human experimentation and with the Helsinki Declaration of 1975 , as revised in 2008 .

\section{References}

Alexander, G. E., DeLong, M. R., \& Strick, P. L. (1986). Parallel organization of functionally segregated circuits linking basal ganglia and cortex. Annual Review of Neuroscience, 9(1), 357-381. Retrieved from https:// www.annualreviews.org/doi/pdf/10.1146/annurev.ne.09.030186.002041.

Allen, M., Poggiali, D., Whitaker, K., Marshall, T. R., \& Kievit, R. A. (2019). Raincloud plots: A multi-platform tool for robust data visualization. Wellcome Open Research, 4, 36. http://doi.org/10.12688/wellcomeopenres. 1519.

American Psychiatric Association (2013). Obsessive-Compulsive and Related Disorders. In Diagnostic and statistical manual of mental disorders (5th ed.). American Psychiatric Association. https://doi.org/10.1176/appi.books. 9780890425596.

Andreescu, C., Sheu, L. K., Tudorascu, D., Walker, S., \& Aizenstein, H. (2014). The ages of anxiety - Differences across the lifespan in the default mode network functional connectivity in generalized anxiety disorder. International Journal of Geriatric Psychiatry, 29(7), 704-712. https:/doi. org/10.1002/gps.4051.

Andrews-Hanna, J. R., Reidler, J. S., Huang, C., \& Buckner, R. L. (2010). Evidence for the default network's role in spontaneous cognition. Journal of Neurophysiology, 104(1), 322-335. https://doi.org/10.1152/jn.00830.2009.

Apergis-Schoute, A. M., Bijleveld, B., Gillan, C. M., Fineberg, N. A., Sahakian, B. J., \& Robbins, T. W. (2018). Hyperconnectivity of the ventromedial prefrontal cortex in obsessive-compulsive disorder. Brain and Neuroscience Advances, 2, 239821281880871. https://doi.org/10.1177/2398212818808710.

Banca, P., Voon, V., Vestergaard, M. D., Philipiak, G., Almeida, I., Pocinho, F., ... Castelo-Branco, M. (2015). Imbalance in habitual versus goal directed neural systems during symptom provocation in obsessive-compulsive disorder. Brain, 138(3), 798-811. https://doi.org/10.1093/brain/awu379.

Beesdo, K., Knappe, S., \& Pine, D. S. (2009). Anxiety and anxiety disorders in children and adolescents: Developmental issues and implications for DSM-V. The Psychiatric clinics of North America, 32(3), 483-524. https:// doi.org/10.1016/j.psc.2009.06.002.

Benjamini, Y., \& Hochberg, Y. (1995). Controlling the false discovery rate: A practical and powerful approach to multiple testing. Journal of the Royal Statistical Society: Series B (Methodological), 57(1), 289-300. https:// doi.org/10.1111/j.2517-6161.1995.tb02031.x.

Bernstein, G. A., Cullen, K. R., Harris, E. C., Conelea, C. A., Zagoloff, A. D., Carstedt, P. A., ... Mueller, B. A. (2019). Sertraline effects on striatal restingstate functional connectivity in youth with obsessive-compulsive disorder: A pilot study. Journal of the American Academy of Child \& Adolescent Psychiatry, 58(5), 486-495. https://doi.org/10.1016/j.jaac.2018.07.897.

Beucke, J. C., Sepulcre, J., Eldaief, M. C., Sebold, M., Kathmann, N., \& Kaufmann, C. (2014). Default mode network subsystem alterations in obsessive-compulsive disorder. British Journal of Psychiatry, 205(5), 376382. https://doi.org/10.1192/bjp.bp.113.137380.

Brakoulias, V., Starcevic, V., Belloch, A., Brown, C., Ferrao, Y. A., Fontenelle, L. F., ... Reddy, Y. C. J. (2017). Comorbidity, age of onset and suicidality in 
obsessive-compulsive disorder (OCD): An international collaboration. Comprehensive Psychiatry, 76, 79-86. https://doi.org/10.1016/j.comppsych. 2017.04.002.

Breiter, H. C., Rauch, S. L., Kwong, K. K., Baker, J. R., Weisskoff, R. M., Kennedy, D. N., ... Stern, C. E. (1996). Functional magnetic resonance imaging of symptom provocation in obsessive-compulsive disorder. Archives of General Psychiatry, 53(7), 595-606. https://doi.org/10.1001/archpsyc.1996.01830070041008.

Brennan, B. P., Tkachenko, O., Schwab, Z. J., Juelich, R. J., Ryan, E. M., Athey, A. J., ... Hudson, J. I. (2015). An examination of rostral anterior cingulate cortex function and neurochemistry in obsessive-compulsive disorder. Neuropsychopharmacology, 40(8), 1866-1876. https://doi.org/10.1038/npp. 2015.36.

Brennan, B. P., Wang, D., Li, M., Perriello, C., Ren, J., Elias, J. A., ... Rauch, S. L. (2019). Use of an individual-level approach to identify cortical connectivity biomarkers in obsessive-compulsive disorder. Biological Psychiatry: Cognitive Neuroscience and Neuroimaging, 4(1), 27-38. https://doi.org/10. 1016/j.bpsc.2018.07.014.

Carmichael, S. T., \& Price, J. L. (1996). Connectional networks within the orbital and medial prefrontal cortex of macaque monkeys. Journal of Comparative Neurology, 371(2), 179-207. Retrieved from https://pubmed. ncbi.nlm.nih.gov/8835726/.

Chase, H. W., Graur, S., Versace, A., Greenberg, T., Hudak, R., Quirk, G. J., ... Phillips, M. L. (2020). Neural mechanisms of persistent avoidance in OCD: A novel avoidance devaluation study. NeuroImage: Clinical, 28, 102404. https://doi.org/10.1016/j.nicl.2020.102404.

Chen, Y. H., Li, S. F., Lv, D., Zhu, G. D., Wang, Y. H., Meng, X., ... Wang, X. P. (2018). Decreased intrinsic functional connectivity of the salience network in drug-naive patients with obsessive-compulsive disorder. Frontiers in Neuroscience, 12, 889. https://doi.org/10.3389/fnins.2018.00889.

Cocchi, L., Harrison, B. J., Pujol, J., Harding, I. H., Fornito, A., Pantelis, C., \& Yücel, M. (2012). Functional alterations of large-scale brain networks related to cognitive control in obsessive-compulsive disorder. Human Brain Mapping, 33(5), 1089-1106. https://doi.org/10.1002/hbm.21270.

de Vries, F. E., de Wit, S. J., van den Heuvel, O. A., Veltman, D. J., Cath, D. C., van Balkom, A. J. L. M., \& van der Werf, Y. D. (2019). Cognitive control networks in OCD: A resting-state connectivity study in unmedicated patients with obsessive-compulsive disorder and their unaffected relatives. World Journal of Biological Psychiatry, 20(3), 230-242. https://doi.org/10. 1080/15622975.2017.1353132.

Di Martino, A., Scheres, A., Margulies, D. S., Kelly, A. M. C., Uddin, L. Q., Shehzad, Z., ... Milham, M. P. (2008). Functional connectivity of human striatum: A resting-state fMRI study. Cerebral Cortex, 18(12), 2735-2747. https://doi.org/10.1093/cercor/bhn041.

Dosenbach, N. U., Fair, D. A., Cohen, A. L., Schlaggar, B. L., \& Petersen, S. E. (2008). A dual-networks architecture of top-down control. Trends in Cognitive Sciences, 12(3), 99-105. https://doi.org/10.1016/j.tics.2008.01.001.

Dosenbach, N. U., Visscher, K. M., Palmer, E. D., Miezin, F. M., Wenger, K. K., Kang, H. C., ... Petersen, S. E. (2006). A core system for the implementation of task sets. Neuron, 50(5), 799-812. https://doi.org/10.1016/j.neuron.2006.04.031.

Fair, D. A., Nigg, J. T., Iyer, S., Bathula, D., Mills, K. L., Dosenbach, N. U. F., ... Milham, M. P. (2013). Distinct neural signatures detected for ADHD subtypes after controlling for micro-movements in resting state functional connectivity MRI data. Frontiers in Systems Neuroscience, 6, 80-80. https://doi.org/10.3389/fnsys.2012.00080.

Fan, J., Zhong, M., Zhu, X., Gan, J., Liu, W., Niu, C., ... Tan, C. (2017). Resting-state functional connectivity between right anterior insula and right orbital frontal cortex correlate with insight level in obsessivecompulsive disorder. NeuroImage: Clinical, 15, 1-7. https://doi.org/10. 1016/j.nicl.2017.04.002.

Fisher, R. A. (1935). The logic of inductive inference. Journal of the Royal Statistical Society, 98(1), 39-82. https://doi-org.proxy.lib.umich.edu/10. 2307/2342435

Fitzgerald, K. D., Liu, Y., Johnson, T. D., Moser, J. S., Marsh, R., Hanna, G. L., \& Taylor, S. F. (2018). Development of posterior medial frontal Cortex function in pediatric obsessive-compulsive disorder. Journal of the American Academy of Child and Adolescent Psychiatry, 57(6), 397-406. https://doi.org/10.1016/j.jaac.2018.02.016.
Fitzgerald, K. D., Liu, Y., Stern, E. R., Welsh, R. C., Hanna, G. L., Monk, C. S. ... Taylor, S. F. (2013). Reduced error-related activation of dorsolateral prefrontal cortex across pediatric anxiety disorders. Journal of the American Academy of Child and Adolescent Psychiatry, 52(11), 1183-1191.e1. https://doi.org/10.1016/j.jaac.2013.09.002.

Fitzgerald, K. D., Schroder, H. S., \& Marsh, R. (2020). Cognitive control in pediatric obsessive compulsive and anxiety disorders: Brain-behavioral targets for early intervention. Biological Psychiatry, 89(7), 697-706. https://doi. org/10.1016/j.biopsych.2020.11.012.

Fitzgerald, K. D., Stern, E. R., Angstadt, M., Nicholson-Muth, K. C., Maynor, M. R., Welsh, R. C., ... Taylor, S. F. (2010). Altered function and connectivity of the medial frontal cortex in pediatric obsessive-compulsive disorder. Biological Psychiatry, 68(11), 1039-1047. https://doi.org/10.1016/j.biopsych. 2010.08.018.

Fitzgerald, K. D., Welsh, R. C., Stern, E. R., Angstadt, M., Hanna, G. L., Abelson, J. L., \& Taylor, S. F. (2011). Developmental alterations of frontal-striatal-thalamic connectivity in obsessive-compulsive disorder Journal of the American Academy of Child and Adolescent Psychiatry, 50 (9), 938-948.e3. https://doi.org/10.1016/j.jaac.2011.06.011.

Fox, M. D., \& Greicius, M. (2010). Clinical applications of resting-state functional connectivity. Frontiers in Systems Neuroscience, 4, 19. https:/doi.org/ 10.3389/fnsys.2010.00019.

Fox, M. D., Snyder, A. Z., Vincent, J. L., Corbetta, M., Van Essen, D. C., \& Raichle, M. E. (2005). The human brain is intrinsically organized into dynamic, anticorrelated functional networks. Proceedings of the National Academy of Sciences, 102(27), 9673-9678. https://doi.org/10.1073/pnas. 0504136102.

Fransson, P., \& Marrelec, G. (2008). The precuneus/posterior cingulate cortex plays a pivotal role in the default mode network: Evidence from a partial correlation network analysis. NeuroImage, 42(3), 1178-1184. https://doi. org/10.1016/j.neuroimage.2008.05.059.

Friston, K. J. (2003). Statistical parametric mapping. In Neuroscience databases (pp. 237-250). Boston, MA: Springer. https://doi.org/10.1007/978-1-46151079-6 16 .

Gehring, W. J., Himle, J., \& Nisenson, L. G. (2000). Action-monitoring dysfunction in obsessive-compulsive disorder. Psychological Science, 11(1), 1-6. https://doi.org/10.1111/1467-9280.00206.

Geller, D. A., Biederman, J., Faraone, S., Agranat, A., Cradock, K., Hagermoser, L., ... Coffey, B. J. (2001). Developmental aspects of obsessive compulsive disorder: Findings in children, adolescents, and adults. The Journal of Nervous and Mental Disease, 189(7), 471-477. https://doi.org/10.1097/ 00005053-200107000-00009.

Gillan, C. M., Apergis-Schoute, A. M., Morein-Zamir, S., Urcelay, G. P., Sule, A., Fineberg, N. A., ... Robbins, T. W. (2015). Functional neuroimaging of avoidance habits in obsessive-compulsive disorder. American Journal of Psychiatry, 172(3), 284-293. https://doi.org/10.1176/appi.ajp.2014.14040525.

Gillan, C. M., Fineberg, N. A., \& Robbins, T. W. (2017). A trans-diagnostic perspective on obsessive-compulsive disorder. Psychological Medicine, 47 (9), 1528-1548. https://doi.org/10.1017/S0033291716002786.

Gillan, C. M., \& Robbins, T. W. (2014). Goal-directed learning and obsessivecompulsive disorder. Philosophical Transactions of the Royal Society B: Biological Sciences, 369(1655). https://doi.org/10.1098/rstb.2013.0475.

Gilmore, J. H., Knickmeyer, R. C., \& Gao, W. (2018). Imaging structural and functional brain development in early childhood. Nature Reviews Neuroscience, 19(3), 123. https://doi.org/10.1038/nrn.2018.1s.

Goldman-Rakic, P. S. (1988). Topography of cognition: Parallel distributed networks in primate association cortex. Annual Review of Neuroscience, 11, 137-156. https://doi.org/10.1146/annurev.ne.11.030188.001033.

Goodman, W. K., Price, L. H., Rasmussen, S. A., Mazure, C., Fleischmann, R. L., Hill, C. L., ... Charney, D. S. (1989). The Yale-Brown obsessive compulsive scale: I. Development, use, and reliability. Archives of General Psychiatry, 46(11), 1006-1011. doi:10.1001/archpsyc.1989.01810110048007

Graybiel, A. M., \& Rauch, S. L. (2000). Toward a neurobiology of obsessivecompulsive disorder. Neuron, 28(2), 343-347. https://doi.org/10.1016/ s0896-6273(00)00113-6.

Grayson, D. S., \& Fair, D. A. (2017). Development of large-scale functional networks from birth to adulthood: A guide to the neuroimaging literature. NeuroImage, 160, 15-31. https://doi.org/10.1016/j.neuroimage.2017.01.079. 
Greicius, M. D., Krasnow, B., Reiss, A. L., \& Menon, V. (2003). Functional connectivity in the resting brain: A network analysis of the default mode hypothesis. Proceedings of the National Academy of Sciences, 100(1), 253258. https://doi.org/10.1073/pnas.0135058100.

Gu, B. M., Park, J. Y., Kang, D. H., Lee, S. J., Yoo, S. Y., Jo, H. J., ... Kwon, J. S. (2008). Neural correlates of cognitive inflexibility during task-switching in obsessive-compulsive disorder. Brain, 131(1), 155-164. https://doi.org/10. 1093/brain/awm 277.

Gusnard, D. A., \& Raichle, M. E. (2001). Searching for a baseline: Functional imaging and the resting human brain. Nature Reviews Neuroscience, 2(10), 685-694. https://doi.org/10.1038/35094500.

Haber, S. N. (2003). The primate basal ganglia: Parallel and integrative networks. Journal of Chemical Neuroanatomy, 26(4), 317-330. https://doi. org/10.1016/j.jchemneu.2003.10.003.

Haber, S. N. (2016). Corticostriatal circuitry. Dialogues in Clinical Neuroscience, 18(1), 7. https://doi.org/10.31887/DCNS.2016.18.1/shaber.

Hajcak, G., Franklin, M. E., Foa, E. B., \& Simons, R. F. (2008). Increased errorrelated brain activity in pediatric obsessive-compulsive disorder before and after treatment. American Journal of Psychiatry, 165(1), 116-123. https:// doi.org/10.1176/appi.ajp.2007.07010143.

Harrison, B. J., Pujol, J., Cardoner, N., Deus, J., Alonso, P., López-Solà, M., ... Soriano-Mas, C. (2013). Brain corticostriatal systems and the major clinical symptom dimensions of obsessive-compulsive disorder. Biological Psychiatry, 73(4), 321-328. https://doi.org/10.1016/j.biopsych.2012.10.006.

Harrison, B. J., Soriano-Mas, C., Pujol, J., Ortiz, H., López-Solà, M., Hernández-Ribas, R., ... Cardoner, N. (2009). Altered corticostriatal functional connectivity in obsessive-compulsive disorder. Archives of General Psychiatry, 66(11), 1189-1200. https://doi.org/10.1001/archgenpsychiatry. 2009.152.

Hauser, T. U., Moutoussis, M., Iannaccone, R., Brem, S., Walitza, S., Drechsler, R., ... Dolan, R. J. (2017). Increased decision thresholds enhance information gathering performance in juvenile obsessive-compulsive disorder (OCD). PLoS Computational Biology, 13(4), 1-19. https://doi.org/10.1371/ journal.pcbi.1005440.

Hou, J., Song, L., Zhang, W., Wu, W., Wang, J., Zhou, D., ... Li, H. (2013). Morphologic and functional connectivity alterations of corticostriatal and default mode network in treatment-naïve patients with obsessivecompulsive disorder. PLoS ONE, 8(12), 1-11. https://doi.org/10.1371/journal.pone.0083931.

Hou, J., Wu, W., Lin, Y., Wang, J., Zhou, D., Guo, J., ... Li, H. (2012). Localization of cerebral functional deficits in patients with obsessivecompulsive disorder: A resting-state fMRI study. Journal of Affective Disorders, 138(3), 313-321. https://doi.org/10.1016/j.jad.2012.01.022.

Hou, J. M., Zhao, M., Zhang, W., Song, L. H., Wu, W. J., Wang, J., ... Qu, W. (2014). Resting-state functional connectivity abnormalities in patients with obsessive-compulsive disorder and their healthy first-degree relatives. Journal of Psychiatry \& Neuroscience: JPN, 39(5), 304. https://doi.org/10. 1503/jpn.130220.

Ivarsson, T., Melin, K., \& Wallin, L. (2008). Categorical and dimensional aspects of co-morbidity in obsessive-compulsive disorder (OCD). European Child \& Adolescent Psychiatry, 17(1), 20-31. https://doi.org/10. 1007/s00787-007-0626-z.

Jang, J. H., Kim, J. H., Jung, W. H., Choi, J. S., Jung, M. H., Lee, J. M., ... Kwon, J. S. (2010). Functional connectivity in fronto-subcortical circuitry during the resting-state in obsessive-compulsive disorder. Neuroscience Letters, 474(3), 158-162. https://doi.org/10.1016/j.neulet.2010.03.031.

Janowitz, D., Grabe, H. J., Ruhrmann, S., Ettelt, S., Buhtz, F., Hochrein, A., ... Wagner, M. (2009). Early onset of obsessive-compulsive disorder and associated comorbidity. Depression and Anxiety, 26(11), 1012-1017. https://doi. org/10.1002/da.20597.

Jung, W. H., Yücel, M., Yun, J. Y., Yoon, Y. B., Cho, K. I. K., Parkes, L., ... Kwon, J. S. (2017). Altered functional network architecture in orbitofronto-striato-thalamic circuit of unmedicated patients with obsessive-compulsive disorder. Human Brain Mapping, 38(1), 109-119. https://doi.org/10.1002/hbm.23347.

Kang, D. H., Jang, J. H., Han, J. Y., Kim, J. H., Jung, W. H., Choi, J. S., ... Kwon, J. S. (2013). Neural correlates of altered response inhibition and dysfunctional connectivity at rest in obsessive-compulsive disorder. Progress in
Neuro-Psychopharmacology and Biological Psychiatry, 40, 340-346. https:// doi.org/10.1016/j.pnpbp.2012.11.001.

Kodaira, M., Iwadare, Y., Ushijima, H., Oiji, A., Kato, M., Sugiyama, N., ... Saito, K. (2012). Poor performance on the Iowa gambling task in children with obsessive-compulsive disorder. Annals of General Psychiatry, 11(1), 16. https://doi.org/10.1186/1744-859X-11-25.

Kolesar, T. A., Bilevicius, E., Wilson, A. D., \& Kornelsen, J. (2019). Systematic review and meta-analyses of neural structural and functional differences in generalized anxiety disorder and healthy controls using magnetic resonance imaging. NeuroImage: Clinical, 24, 102016. https://doi.org/10.1016/j.nicl. 2019.102016.

Lewis, M., \& Kim, S. J. (2009). The pathophysiology of restricted repetitive behavior. Journal of Neurodevelopmental Disorders, 1(2), 114-113 https:// doi.org/10.1007/s11689-009-9019-6.

Maltby, N., Tolin, D. F., Worhunsky, P., O’Keefe, T. M., \& Kiehl, K. A. (2005). Dysfunctional action monitoring hyperactivates frontal-striatal circuits in obsessive-compulsive disorder: An event-related fMRI study. NeuroImage, 24(2), 495-503. https://doi.org/10.1016/j.neuroimage.2004.08.041.

Marek, S., \& Dosenbach, N. U. (2019). Control networks of the frontal lobes. Handbook of Clinical Neurology, 163, 333-347. https://doi.org/10.1016/ B978-0-12-804281-6.00018-5.

Marek, S., Hwang, K., Foran, W., Hallquist, M. N., \& Luna, B. (2015). The contribution of network organization and integration to the development of cognitive control. PLoS Biology, 13(12), e1002328. https://doi.org/10.1371/ journal.pbio.1002328.

Masi, G., Millepiedi, S., Perugi, G., Pfanner, C., Berloffa, S., Pari, C., ... Akiskal, H. S. (2010). A naturalistic exploratory study of the impact of demographic, phenotypic and comorbid features in pediatric obsessive-compulsive disorder. Psychopathology, 43(2), 69-78. https://doi.org/10.1159/000274175.

Mathes, B. M., Morabito, D. M., \& Schmidt, N. B. (2019). Epidemiological and clinical gender differences in OCD. Current Psychiatry Reports, 21(5), 36. https://doi.org/10.1007/s11920-019-1015-2.

Mathis, M. A. D., Alvarenga, P. D., Funaro, G., Torresan, R. C., Moraes, I., Torres, A. R., ... Hounie, A. G. (2011). Gender differences in obsessivecompulsive disorder: A literature review. Brazilian Journal of Psychiatry, 33(4), 390-399. https://doi.org/10.1590/S1516-44462011000400014.

Menon, V. (2011). Large-scale brain networks and psychopathology: A unifying triple network model. Trends in Cognitive Sciences, 15(10), 483-506. https://doi.org/10.1016/j.tics.2011.08.003.

Menzies, L., Chamberlain, S. R., Laird, A. R., Thelen, S. M., Sahakian, B. J., \& Bullmore, E. T. (2008). Integrating evidence from neuroimaging and neuropsychological studies of obsessive-compulsive disorder: The orbitofronto-striatal model revisited. Neuroscience and Biobehavioral Reviews, 32(3), 525-549. https://doi.org/10.1016/j.neubiorev.2007.09.005.

Merikangas, K. R., He, J. P., Burstein, M., Swanson, S. A., Avenevoli, S., Cui, L., .. Swendsen, J. (2010). Lifetime prevalence of mental disorders in US adolescents: Results from the national comorbidity survey replication-adolescent supplement (NCS-A). Journal of the American Academy of Child \& Adolescent Psychiatry, 49(10), 980-989. https://doi.org/10.1016/j.jaac.2010.05.017.

Mesulam, M. M. (1990). Large-scale neurocognitive networks and distributed processing for attention, language, and memory. Annals of Neurology, 28(5), 597-613. https://doi.org/10.1002/ana.410280502.

Morillo, C., Belloch, A., \& García-Soriano, G. (2007). Clinical obsessions in obsessive-compulsive patients and obsession-relevant intrusive thoughts in non-clinical, depressed and anxious subjects: Where are the differences?. Behaviour Research and Therapy, 45(6), 1319-1333. https:/doi.org/10.1016/ j.brat.2006.11.005.

Moser, J. S. (2017). The nature of the relationship between anxiety and the error-related negativity across development. Current Behavioral Neuroscience Reports, 4(4), 309-321. https://doi.org/10.1007/s40473-017-0132-7.

Nakao, T., Okada, K., \& Kanba, S. (2014). Neurobiological model of obsessivecompulsive disorder: Evidence from recent neuropsychological and neuroimaging findings. Psychiatry and Clinical Neurosciences, 68(8), 587-605. https://doi.org/10.1111/pcn.12195.

Neta, M., Schlaggar, B. L., \& Petersen, S. E. (2014). Separable responses to error, ambiguity, and reaction time in cingulo-opercular task control regions. NeuroImage, 99, 59-68. https://doi.org/10.1016/j.neuroimage. 2014.05.053. 
Norman, L. J., Carlisi, C. O., Christakou, A., Murphy, C. M., Chantiluke, K., Giampietro, V., ... Rubia, K. (2018). Frontostriatal dysfunction during decision making in attention-deficit/hyperactivity disorder and obsessivecompulsive disorder. Biological Psychiatry: Cognitive Neuroscience and Neuroimaging, 3(8), 694-703. https://doi.org/10.1016/j.bpsc.2018.03.009.

Norman, L. J., Mannella, K. A., Yang, H., Angstadt, M., Abelson, J. L., Himle, J. A., ... Taylor, S. F. (2021). Treatment-specific associations between brain activation and symptom reduction in OCD following CBT: A randomized fMRI trial. American Journal of Psychiatry, 178(1), 39-47. https://doi.org/ 10.1176/appi.ajp.2020.19080886.

Norman, L. J., Taylor, S. F., Liu, Y., Radua, J., Chye, Y., De Wit, S. J., ... Fitzgerald, K. (2019). Error processing and inhibitory control in obsessivecompulsive disorder: A meta-analysis using statistical parametric maps. Biological Psychiatry, 85(9), 713-725. https://doi.org/10.1016/j.biopsych. 2018.11.010

Peng, Z. W., Xu, T., He, Q. H., Shi, C. Z., Wei, Z., Miao, G. D., ... Chan, R. C. K. (2014). Default network connectivity as a vulnerability marker for obsessive compulsive disorder. Psychological Medicine, 44(7), 14751484. https://doi.org/10.1017/S0033291713002250.

Peterson, A., Thome, J., Frewen, P., \& Lanius, R. A. (2014). Resting-state neuroimaging studies: A new way of identifying differences and similarities among the anxiety disorders? Canadian Journal of Psychiatry, 59(6), 294300. https://doi.org/10.1177/070674371405900602.

Pitman, R. K. (1987). A cybernetic model of obsessive-compulsive psychopathology. Comprehensive Psychiatry, 28(4), 334-343. https:/doi.org/10.1016/ 0010-440X(87)90070-8.

Posner, J., Marsh, R., Maia, T. V., Peterson, B. S., Gruber, A., \& Simpson, H. B. (2014). Reduced functional connectivity within the limbic cortico-striato-thalamo-cortical loop in unmedicated adults with obsessivecompulsive disorder. Human Brain Mapping, 35(6), 2852-2860. https://doi. org/10.1002/hbm.22371.

Posner, J., Song, I., Lee, S., Rodriguez, C. I., Moore, H., Marsh, R., \& Simpson, H. B. (2017). Increased functional connectivity between the default mode and salience networks in unmedicated adults with obsessive-compulsive disorder. Human Brain Mapping, 38(2), 678-687. https://doi.org/10.1002/ hbm.23408.

Power, J. D., Cohen, A. L., Nelson, S. M., Wig, G. S., Barnes, K. A., Church, J. A., ... Petersen, S. E. (2011). Functional network organization of the human brain. Neuron, 72(4), 665-678. https://doi.org/10.1016/j.neuron.2011.09.006.

Rabany, L., Diefenbach, G. J., Bragdon, L. B., Pittman, B. P., Zertuche, L., Tolin, D. F., ... Assaf, M. (2017). Resting-state functional connectivity in generalized anxiety disorder and social anxiety disorder: Evidence for a dimensional approach. Brain Connectivity, 7(5), 289-298. https://doi.org/ 10.1089/brain.2017.0497.

Rosenberg, D. R., \& Keshavan, M. S. (1998). Toward a neurodevelopmental model of obsessive-compulsive disorder. Biological Psychiatry, 43(9), 623-640. https://doi.org/10.1016/S0006-3223(97)00443-5.

Ruscio, A. M., Stein, D. J., Chiu, W. T., \& Kessler, R. C. (2010). The epidemiology of obsessive-compulsive disorder in the national comorbidity survey replication. Molecular Psychiatry, 15, 53-63. https://doi.org/10.1038/ mp.2008.94.

Sadaghiani, S., \& D'Esposito, M. (2015). Functional characterization of the cingulo-opercular network in the maintenance of tonic alertness. Cerebral Cortex, 25(9), 2763-2773. https://doi.org/10.1093/cercor/bhu072.

Sakai, Y., Narumoto, J., Nishida, S., Nakamae, T., Yamada, K., Nishimura, T., \& Fukui, K. (2011). Corticostriatal functional connectivity in nonmedicated patients with obsessive-compulsive disorder. European Psychiatry, 26(7), 463-469. https://doi.org/10.1016/j.eurpsy.2010.09.005.

Saxena, S., \& Rauch, S. L. (2000). Functional neuroimaging and the neuroanatomy of obsessive-compulsive disorder. Psychiatric Clinics of North America, 23(3), 563-586. https://doi.org/10.1016/S0193-953X(05)70181-7.

Seeley, W. W., Menon, V., Schatzberg, A. F., Keller, J., Glover, G. H., Kenna, H., ... Greicius, M. D. (2007). Dissociable intrinsic connectivity networks for salience processing and executive control. Journal of Neuroscience, 27(9), 2349-2356. https://doi.org/10.1523/JNEUROSCI. 5587-06.2007.

Sestieri, C., Corbetta, M., Spadone, S., Romani, G. L., \& Shulman, G. L. (2014). Domain-general signals in the cingulo-opercular network for visuospatial attention and episodic memory. Journal of Cognitive Neuroscience, 26(3), 551-568. https://doi.org/10.1162/jocn_a_00504.

Shanmugan, S., Wolf, D. H., Calkins, M. E., Moore, T. M., Ruparel, K., Hopson, R. D., ... Gennatas, E. D. (2016). Common and dissociable mechanisms of executive system dysfunction across psychiatric disorders in youth. American Journal of Psychiatry, 173(5), 517-526. https://doi.org/ 10.1176/appi.ajp.2015.15060725.

Shulman, G. L., Corbetta, M., Buckner, R. L., Fiez, J. A., Miezin, F. M., Raichle, M. E., \& Petersen, S. E. (1997). Common blood flow changes across visual tasks: I. Increases in subcortical structures and cerebellum but not in nonvisual cortex. Journal of Cognitive Neuroscience, 9(5), 624-647. https://doi. org/10.1162/jocn.1997.9.5.624.

Smith, S. M., Jenkinson, M., Woolrich, M. W., Beckmann, C. F., Behrens, T. E., Johansen-Berg, H., ... Niazy, R. K. (2004). Advances in functional and structural MR image analysis and implementation as FSL. NeuroImage 23, S208-S219. https://doi.org/10.1016/j.neuroimage.2004.07.051.

Stern, E. R., Fitzgerald, K. D., Welsh, R. C., Abelson, J. L., \& Taylor, S. F. (2012). Resting-state functional connectivity between fronto-parietal and default mode networks in obsessive-compulsive disorder. PLoS ONE, 7 (5), e36356. https://doi.org/10.1371/journal.pone.0036356.

Stern, E. R., Welsh, R. C., Fitzgerald, K. D., Gehring, W. J., Lister, J. J., Himle, J. A., ... Taylor, S. F. (2011). Hyperactive error responses and altered connectivity in ventromedial and frontoinsular cortices in obsessive-compulsive disorder. Biological Psychiatry, 69(6), 583-591. https://doi.org/10.1016/j. biopsych.2010.09.048.

Sylvester, C. M., Corbetta, M., Raichle, M. E., Rodebaugh, T. L., Schlaggar, B. L., Sheline, Y. I., ... Lenze, E. J. (2012). Functional network dysfunction in anxiety and anxiety disorders. Trends in Neurosciences, 35(9), 527-535. https://doi.org/10.1016/j.tins.2012.04.012.

Tanidir, C., Adaletli, H., Gunes, H., Kilicoglu, A. G., Mutlu, C., Bahali, M. K., ... Uneri, O. S. (2015). Impact of gender, age at onset, and lifetime tic disorders on the clinical presentation and comorbidity pattern of obsessive-compulsive disorder in children and adolescents. Journal of Child and Adolescent Psychopharmacology, 25(5), 425-431. https://doi.org/10.1089/cap.2014.0120.

Thomas Yeo, B. T., Krienen, F. M., Sepulcre, J., Sabuncu, M. R., Lashkari, D., Hollinshead, M., ... Buckner, R. L. (2011). The organization of the human cerebral cortex estimated by intrinsic functional connectivity. Journal of Neurophysiology, 106(3), 1125-1165. https://doi.org/10.1152/jn.00338.2011.

Tian, L., Meng, C., Jiang, Y., Tang, Q., Wang, S., Xie, X., ... Wang, J. (2016). Abnormal functional connectivity of brain network hubs associated with symptom severity in treatment-naive patients with obsessive-compulsive disorder: A resting-state functional MRI study. Progress in Neuro-Psychopharmacology and Biological Psychiatry, 66, 104-111. https:// doi.org/10.1016/j.pnpbp.2015.12.003.

Tomiyama, H., Nakao, T., Murayama, K., Nemoto, K., Ikari, K., Yamada, S., ... Kanba, S. (2019). Dysfunction between dorsal caudate and salience network associated with impaired cognitive flexibility in obsessive-compulsive disorder: A resting-state fMRI study. NeuroImage: Clinical, 24, 102004 https://doi.org/10.1016/j.nicl.2019.102004.

Woodward, N. D., \& Cascio, C. J. (2015) Resting-state functional connectivity in psychiatric disorders. JAMA Psychiatry. 72(8), 743-744. doi:10.1001/ jamapsychiatry.2015.0484.

Xu, J., Van Dam, N. T., Feng, C., Luo, Y., Ai, H., Gu, R., \& Xu, P. (2019). Anxious brain networks: A coordinate-based activation likelihood estimation meta-analysis of resting-state functional connectivity studies in anxiety. Neuroscience \& Biobehavioral Reviews, 96, 21-30. https://doi.org/10.1016/j. neubiorev.2018.11.005.

Yan, C. G., Wang, X. D., Zuo, X. N., \& Zang, Y. F. (2016). DPABI: Data processing \& analysis for (resting-state) brain imaging. Neuroinformatics, 14(3), 339-351. https://doi.org/10.1007/s12021-016-9299-4.

Yun, J. Y., Boedhoe, P. S. W., Vriend, C., Jahanshad, N., Abe, Y., Ameis, S. H., ... Kwon, J. S. (2020). Brain structural covariance networks in obsessivecompulsive disorder: A graph analysis from the ENIGMA consortium. Brain, 143(2), 684-700. https://doi.org/10.1093/brain/awaa001.

Zhang, C., Dougherty, C. C., Baum, S. A., White, T., \& Michael, A. M. (2018). Functional connectivity predicts gender: Evidence for gender differences in resting brain connectivity. Human Brain Mapping, 39(4), 1765-1776. https://doi.org/10.1002/hbm.23950. 